\title{
Metal-organic complexation in the marine environment
}

\author{
George W. Luther III, ${ }^{a}{ }^{a}$ Timothy F. Rozan, ${ }^{a}$ Amy Witter ${ }^{b}$ and Brent Lewis ${ }^{c}$ \\ ${ }^{a}$ College of Marine Studies, University of Delaware, Lewes, DE 19958, USA. \\ E-mail: luther@udel.edu \\ ${ }^{b}$ Chemistry Department, Dickinson College, Carlisle, PA 17013, USA \\ ${ }^{c}$ Science \& Math Department, Kettering University, Flint, MI 48504, USA
}

Received 2nd July 2001, Accepted 19th September 2001

Published on the Web 28th September 2001

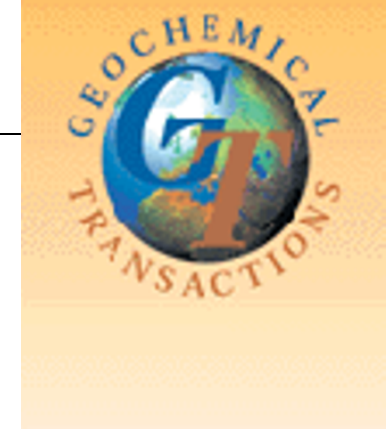

Article

We discuss the voltammetric methods that are used to assess metal-organic complexation in seawater. These consist of titration methods using anodic stripping voltammetry (ASV) and cathodic stripping voltammetry competitive ligand experiments (CSV-CLE). These approaches and a kinetic approach using CSV-CLE give similar information on the amount of excess ligand to metal in a sample and the conditional metal ligand stability constant for the excess ligand bound to the metal. CSV-CLE data using different ligands to measure $\mathrm{Fe}(\mathrm{III})$ organic complexes are similar. All these methods give conditional stability constants for which the side reaction coefficient for the metal can be corrected but not that for the ligand. Another approach, pseudovoltammetry, provides information on the actual metal-ligand complex(es) in a sample by doing ASV experiments where the deposition potential is varied more negatively in order to destroy the metal-ligand complex. This latter approach gives concentration information on each actual ligand bound to the metal as well as the thermodynamic stability constant of each complex in solution when compared to known metal-ligand complexes. In this case the side reaction coefficients for the metal and ligand are corrected. Thus, this method may not give identical information to the titration methods because the excess ligand in the sample may not be identical to some of the actual ligands binding the metal in the sample.

\section{Introduction}

In the last two decades, our knowledge of trace metal speciation has grown tremendously. With the advent of trace metal clean sampling techniques ${ }^{1}$ and sensitive voltammetric techniques, ${ }^{2-4}$ the marine community now recognizes that metal speciation in seawater and estuarine waters is dominated by complexation with organic compounds of unknown composition and origin. ${ }^{5-12}$ Recent culture work ${ }^{13-18}$ has shown that microorganisms produce a variety of low molecular weight organic compounds that complex metals with high stability constants. These compounds have a variety of functional groups that include phosphate, carboxylic acids, amines, thiol and hydroxy groups. Specific functional groups such as hydroxamate, catecholate and $\beta$-hydroxyaspartate are bidentate groups and organisms make molecules with three bidentate groups in a molecule. ${ }^{14,19-21}$ In addition, plant degradation products $^{22-30}$ such as porphyrins are significant organic ligands that bind metals through four $\mathrm{N}$ atoms in a square planar arrangement. These latter multidentate molecules have very high stability constants with metals and are also kinetically inert to metal-ligand dissociation processes. ${ }^{31-34}$ For this reason, organisms generally uptake the free metal ion rather than a metal-ligand form. ${ }^{35,36}$ Thus, an understanding of metal-organism interactions requires an understanding of the amount of dissolved free ion present relative to the total dissolved metal concentration as well as the metal acquisition methods that an organism can use. ${ }^{35-37}$

In this paper we review and compare the principal voltammetric methods, which provide evidence for metalorganic complexes. Most voltammetric work is performed with the hanging mercury drop electrode (HMDE) or the rotating disk electrode (RDE) with a thin mercury film (TMF) because these permit the measurement of metal-organic complexation at (sub)nanomolar levels directly in the solution of interest. The actual experimental methods can be broken into two broad categories and are based on the electrochemical behavior of the metal bound to an organic ligand.

The first method consists of titration experiments that measure the amount of ligand in excess to the metal in the solution $^{38-44}$ and the conditional stability constant, $K_{\text {cond }} \mathrm{M}^{\prime} \mathrm{L}$, for the excess ligand with the metal. The $K_{\text {cond } \mathrm{M}^{\prime} \mathrm{L}}$ is generally assumed to be a 1:1 metal-ligand complex and is given by

$$
K_{\text {cond } \mathrm{M}^{\prime} \mathrm{L}}=[\mathrm{ML}] /\left(\left[\mathrm{M}^{\prime}\right]\left[\mathrm{L}^{\prime}\right]\right)
$$

where $\mathrm{M}^{\prime}$ and $\mathrm{L}^{\prime}$ are the concentrations of the metal and ligand that are not bound to each other. These are related to the total metal $[\mathrm{M}]_{\mathrm{T}}$ and $[\mathrm{L}]_{\mathrm{T}}$ via

$$
\left[\mathrm{M}^{\prime}\right]=[\mathrm{M}]_{\mathrm{T}}-[\mathrm{ML}] \text { and }\left[\mathrm{L}^{\prime}\right]=[\mathrm{L}]_{\mathrm{T}}-[\mathrm{ML}] \text {. }
$$

The free metal $\left[\mathrm{M}^{n+}\right]$ plus the metal bound to other inorganic ligands equals $\left[\mathrm{M}^{\prime}\right]$,

$$
\left[\mathrm{M}^{\prime}\right]=\left[\mathrm{M}^{n+}\right]+\Sigma \mathrm{MX}_{i}
$$

and the fraction of free metal in the solution without the organic ligand is given by

$$
\left[\mathrm{M}^{n+}\right]=\left[\mathrm{M}^{\prime}\right] \alpha_{\mathrm{M}}
$$

where

$$
\alpha_{\mathrm{M}}=1 /\left(1+\Sigma K_{\mathrm{MX}_{i}}[\mathrm{X}]_{i}\right)
$$

This has also been expressed as the side reaction coefficient for $\mathrm{M}^{\prime}, \alpha_{\mathrm{M}^{\prime}}$, which is the reciprocal of $\alpha_{\mathrm{M}}$ or

$$
\alpha_{\mathbf{M}^{\prime}}=\left[\mathrm{M}^{\prime}\right] /\left[\mathrm{M}^{n+}\right]
$$


The conditional constant for $\mathrm{M}^{\prime} \mathrm{L}$ is related to $\mathrm{M}^{n+} \mathrm{L}$ by

$$
K_{\text {cond } \mathrm{ML}}=[\mathrm{ML}] /\left(\left[\mathrm{M}^{n+}\right]\left[\mathrm{L}^{\prime}\right]\right)=K_{\text {cond } \mathrm{M}^{\prime} \mathrm{L}}\left(\alpha_{\mathrm{M}^{\prime}}\right)
$$

Similar equations can be written for the organic ligand to give a thermodynamic constant,

$$
K_{\text {therm }}=[\mathrm{ML}] /\left(\left[\mathrm{M}^{n+}\right]\left[\mathrm{L}^{n-}\right]\right)=K_{\text {cond } \mathrm{M}^{\prime} \mathrm{L}}\left(\alpha_{\mathrm{M}^{\prime}}\right)\left(\alpha_{\mathrm{L}^{\prime}}\right)
$$

but in environmental samples the interactions of $\mathrm{H}^{+}, \mathrm{Ca}^{2+}$ and $\mathrm{Mg}^{2+}$ with the ligand are unknown.

The titration experiments include (1) anodic stripping voltammetry $^{2}$ (ASV), which is useful for metals that react at the electrode directly $\left(\mathrm{Cu}^{2+}, \mathrm{Zn}^{2+}, \mathrm{Cd}^{2+}, \mathrm{Pb}^{2+}\right)$, and (2) cathodic stripping voltammetry/competitive ligand exchange $^{3,8,9}$ (CSV-CLE) which is useful for metals that do not react at the electrode directly but have a metal-ligand complex that does $\left(\mathrm{Fe}^{3+}, \mathrm{Co}^{2+}\right)$. The CSV-CLE method depends on the measurement of a known metal-ligand complex (the competing ligand), that adsorbs to the mercury electrode. In addition, a kinetic CSV-CLE approach ${ }^{10-12}$ for excess ligand binding a metal has been used to measure the metal organic formation rate constant $\left(k_{\mathrm{f}}\right)$, dissociation rate constant $\left(k_{\mathrm{d}}\right)$, the half-life or residence time $\left(t_{1 / 2}\right)$ of the complex and $K_{\text {cond } \mathrm{M}^{\prime} \mathrm{L}}$ (from $k_{\mathrm{f}} / k_{\mathrm{d}}$ ). The second type of voltammetry method involves the breakdown of the actual complex in situ and is termed pseudovoltammetry, ${ }^{45-48}$ which is useful for metals that react at the electrode directly. This method gives information on the amount of ligand binding to a specific complex with a thermodynamic constant, $K_{\text {therm }}$, that differs from $K_{\text {cond }}$ ML. $K_{\text {cond } M L}$ is corrected for the side reaction coefficient of the metal but not the ligand whereas $K_{\text {therm }}$ is corrected for the side reaction coefficients of the metal and ligand via comparison to metal-ligand complexes of known $K_{\text {therm }}$ (chelate scale).

We describe the use of these methods for unknown ligands in seawater as well as with model ligands in UV irradiated seawater for the metals $\mathrm{Cu}$ (II), $\mathrm{Zn}$ (II) and $\mathrm{Fe}$ (III). In the case of CSV-CLE, we show for known Fe(III)-organic complexes that the use of different ligands [1-nitroso-2-napthol, or 1N2N, and salicylaldoxime, or SAL) gives comparable $K$ and ligand concentration data.

\section{Experimental}

The details of the experimental procedures for ASV and pseudovoltammetry work have been previously described by our group. ${ }^{45,46}$ Total $\mathrm{Zn}$ and $\mathrm{Cu}$ concentrations were performed using the method of Bruland et al. ${ }^{1}$ CSV-CLE and kinetic $\mathrm{Fe}(\mathrm{III})$ measurements with $1 \mathrm{~N} 2 \mathrm{~N}$ were performed as we have outlined previously. ${ }^{10-12}$ CSV-CLE experiments with SAL were performed as described by Rue and Bruland. ${ }^{6,7}$ Examples of model ligands commonly used in experiments are given in Appendices 1 and 2. Appendix 2 shows types of strong ligands (functional groups are circled) that bind to $\mathrm{Fe}(\mathrm{III})$ and which may bind to other metals.

\section{Results and discussion}

\section{Metal-ligand complexes}

Voltammetry can provide information on a ligand actually binding a metal because many metal-ligand complexes give a discrete peak or half-wave potential. In a sample, these peaks can be compared to known ligand-metal complexes in the form of a metal-chelate scale (see pseudovoltammetry below). Fig. 1A shows the voltammetric reduction of inorganic $\mathrm{Zn}$ (II) in UV irradiated seawater $\left(E_{\mathrm{p}}=-1.05 \mathrm{~V}\right)$ and Fig. $1 \mathrm{~B}$ shows the reduction when $\mathrm{Zn}$ (II) is bound to two nitrilotriacetic acid molecules (NTA; $E_{\mathrm{p}}=-1.52 \mathrm{~V}$ ). The reduction is more negative for the $\mathrm{Zn}$ complex with NTA than for inorganic

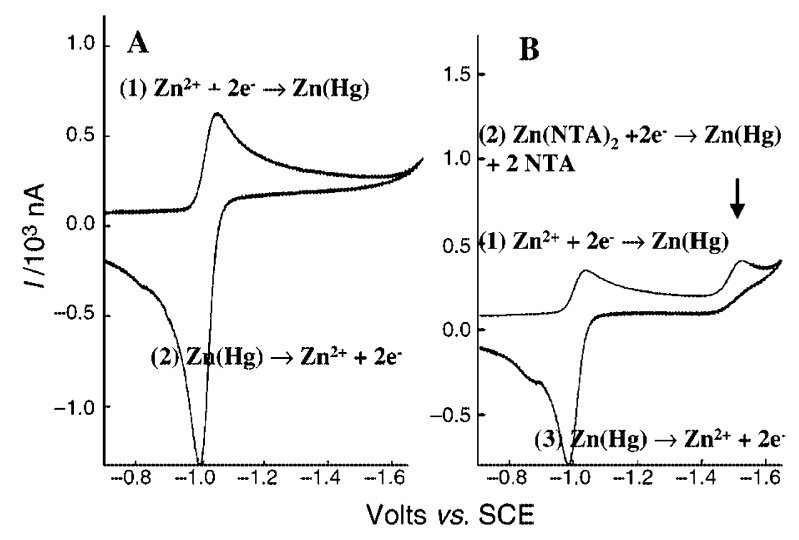

Fig. 1 Cyclic voltammograms of (A) $100 \mu \mathrm{M}$ inorganic $\mathrm{Zn}$ in seawater and (B) $100 \mu \mathrm{M} Z n$ with $50 \mu \mathrm{M}$ NTA. Peak 2 is due to the reduction of $\mathrm{Zn}$ in $\mathrm{ZnNTA}_{2}$. Peak 1 in each $\mathrm{CV}$ is due to inorganic $\mathrm{Zn}$ reduction and peak 3 is due to the oxidation of $\mathrm{Zn}$ in the amalgam.

$\mathrm{Zn}$ (II) because the ligand donates electrons more strongly than simple monodentate ligands such as chloride and hydroxide. In addition, two to four atoms in one NTA molecule can bind to $\mathrm{Zn}$ (II) and the displacement of monodentate inorganic ligands by multidentate ligands gives rise to higher stability constants via the "chelate" effect which is an entropy driven reaction; i.e., there are more product molecules than reactant molecules for the reaction ${ }^{49}$ (generalized eqn. (1) and (2); charges omitted for simplicity).

$$
\mathrm{M}\left(\mathrm{H}_{2} \mathrm{O}\right)_{6}+\mathrm{L}-\mathrm{L} \rightarrow \mathrm{M}\left(\mathrm{H}_{2} \mathrm{O}\right)_{4}(\mathrm{~L}-\mathrm{L})+2 \mathrm{H}_{2} \mathrm{O}
$$

where $\mathrm{L}-\mathrm{L}$ indicates a bidentate ligand

$$
\Delta G=\Delta H-T \Delta S=-R T \ln K
$$

Every ligand that reacts with a metal can have a unique reduction potential that can be used for analysis and this is the basis for both the CSV-CLE and pseudovoltammetry approaches.

\section{ASV titrations}

We first discuss the titration approach for the measurement of metal-organic ligand complexes for metals that react directly at the $\mathrm{Hg}$ electrode (ASV experiment). In titration experiments, metal is added to an unknown sample and the inorganic form of the metal (e.g., Fig 1A for inorganic $\mathrm{Zn}$ indicates that the deposition potential should be more negative than $-1.1 \mathrm{~V}$ ) is analyzed via deposition experiments for possible reaction at the $\mathrm{Hg}$ electrode. More than $95-99 \%$ of the metal is normally bound to an unknown organic compound(s), which is in excess to the metal in the sample. Fig. 2A shows that the inorganic $\mathrm{Zn}$ reduction peak from a Delaware Bay sample is suppressed until the excess ligand has been titrated by the addition of inorganic $\mathrm{Zn}$. Linearization of the titration data is typically performed by use of the Langmuir or Ruzic transformation ${ }^{38-41}$ [eqn. (3)] or the Scatchard transformation ${ }^{39}$ [eqn. (4)]. For the Langmuir linearization (Fig. 2B),

$$
\frac{[\mathrm{M}]}{[\mathrm{ML}]}=\frac{[\mathrm{M}]}{C_{\mathrm{L}}}+\frac{\alpha_{\mathrm{M}^{\prime}}}{\left(K_{\text {cond } \mathrm{ML}} C_{\mathrm{L}}\right)}
$$

a plot of $[\mathrm{M}] /[\mathrm{ML}])$ vs. $[\mathrm{M}]$ yields a straight line with slope $C_{\mathrm{L}}$ from which $K_{\text {cond }} \mathrm{ML}$ (the conditional stability constant uncorrected for the side reaction coefficient of the ligand) can be evaluated from the intercept. Note that $\mathrm{M}_{\mathrm{T}}-[\mathrm{M}]=[\mathrm{ML}]$, $[\mathrm{M}]$ is the labile or inorganic $\mathrm{M}$, and $\alpha_{\mathrm{M}^{\prime}}$ is the side reaction coefficient of the metal ion $\left(\alpha_{\mathrm{M}^{\prime}}\right.$ for the divalent cations of the 

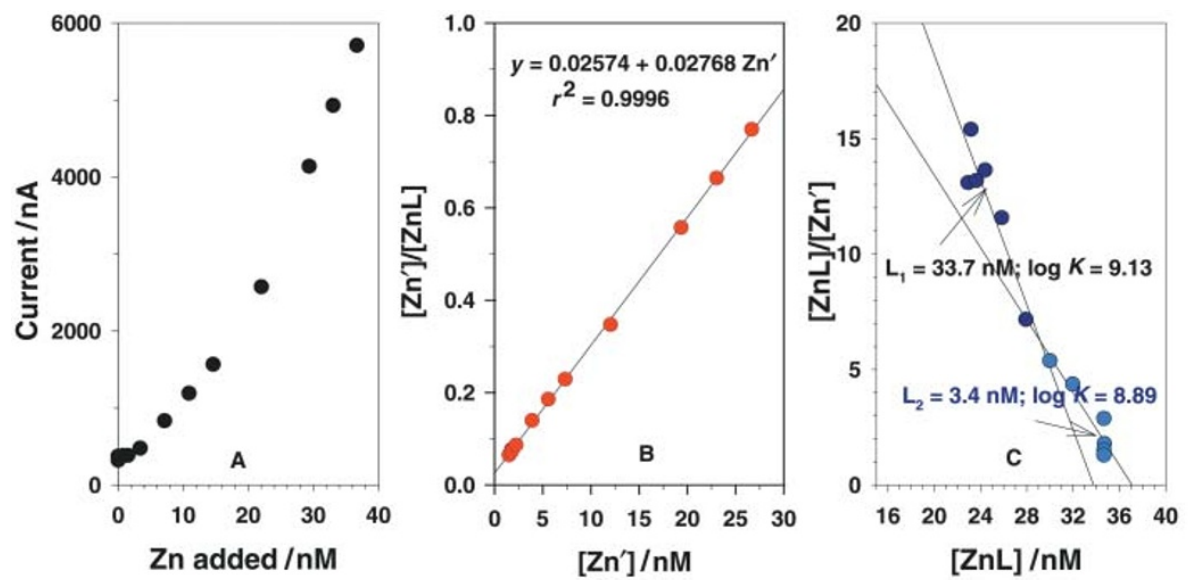

Fig. 2 ASV titration of a Delaware Bay sample (A); Langmuir transformation of the titration data (B) and Scatchard-Langmuir transformation of the titration data. $1 /$ slope $=[\mathrm{L}]=36.1 \mathrm{nM}$ and $K=1 /($ intercept[L]) $(\log K=9.03)$.

first transition series in seawater is usually $<0.2 \log K$ units). ${ }^{50,51}$ In Fig. 2B, the linearization plot for data in Fig. 2A shows that there is a single straight line showing only one complex with a $C_{\mathrm{L}}=36.1 \mathrm{nM}$ and a $\log K_{\text {cond } \mathrm{ML}}=9.03$.

The Scatchard transformation is given by eqn. (4) and shown in Fig. 2C for the

$$
\frac{[\mathrm{ML}]}{[\mathrm{M}]}=K_{\text {cond } \mathrm{ML}}\left[C_{\mathrm{L}}\right]-K_{\text {cond ML }}[\mathrm{ML}]
$$

data in Fig. 2A. A plot of $[\mathrm{ML}] /[\mathrm{M}] v s$. [ML] gives a slope which is $K_{\text {cond } \mathrm{ML}}$ and $\left[C_{\mathrm{L}}\right]$ is the $x$-intercept for the regression line. In this linearization, two separate slopes are noted with a total ligand content of $37.1 \mathrm{nM}$. These data suggest that two ligands or ligand classes may be present in the sample. By convention, $\mathrm{L}_{1}$ is the stronger ligand with a higher $\log K_{\text {cond }} \mathrm{ML}$ of 9.13 (concentration $=33.7 \mathrm{nM}$ ) and $\mathrm{L}_{2}$ is the weaker ligand with a smaller $\log K_{\text {cond ML }}$ of 8.89 (concentration is $37.1-$ $33.7=3.4 \mathrm{nM}$ ). The Scatchard transformation is usually the better of the linearization methods for determining separate ligand classes especially when the $\log K_{\text {cond ML }}$ data are similar. More recently, non-linear methods ${ }^{42}$ have been gaining popularity.

It is important to reiterate that the $K_{\text {cond ML }}$ data cannot be corrected for the side reaction coefficient of the unknown ligand in samples. Bruland ${ }^{2}$ showed that the $\mathrm{Zn}$-EDTA complex has a $\log K_{\text {cond } \mathrm{ML}}=7.9$ in UV seawater but $\log$ $K_{\text {cond } \mathrm{ML}}>11$ in $0.1 \mathrm{M} \mathrm{KCl}$ of the same $\mathrm{pH}$. The difference in these constants is due to the interaction of $\mathrm{Ca}$ and $\mathrm{Mg}$ in seawater with the carboxylic acid functional groups of EDTA. However, the actual thermodynamic constant for $\mathrm{Zn}-$ EDTA is $\log K_{\text {therm }}=16.3$. The fact that a $\log K_{\text {cond ML }}>11$ is calculated indicates that there is a titration window for these types of ASV titration experiments. The titration window depends on the concentration of the unknown ligand and the metal. In general, there is a window of about six $\log K$ units for these types of titrations.

\section{CSV-CLE titrations}

Any known metal-organic complex, which gives a voltammetry signal, can be used to study the interactions of that metal with an unknown ligand(s) in a sample. In this example, the known ligand is a competitive ligand, one competing for the metal in a sample. This approach must be used for metals such as $\mathrm{Fe}(\mathrm{III})^{3,6,12}$ and $\mathrm{Co}(\mathrm{III})^{8,9}$ that do not react directly at the mercury electrode. Several studies have also used this approach for metals ${ }^{40,41,44,46}$ such as $\mathrm{Zn}$ and $\mathrm{Cu}$, which can be measured at the electrode. Comparison of the ASV and CSV-CLE methods ${ }^{44}$ for these metals shows similar $\left[C_{\mathrm{L}}\right]$ and $K_{\text {cond }} \mathrm{ML}$ data.

In the CSV-CLE case, metal in increasing concentration (from zero added metal) is added to a series of electrochemical cells containing the sample with the same amount of a competitive ligand. After analyzing each electrochemical cell, a plot similar to Fig. 2A results. Linearization of the data is given in eqn. (5), which is identical to eqn. (4)

$$
\frac{[\mathrm{M}]}{[\mathrm{ML}]}=\frac{[\mathrm{M}]}{C_{\mathrm{L}}}+\frac{\left(\alpha_{\mathrm{M}^{\prime}}+\alpha_{\mathrm{ML}}\right)}{\left(K_{\mathrm{cond} \mathrm{ML}} C_{\mathrm{L}}\right)}
$$

except for $\alpha_{\mathrm{ML}}$, which is the side reaction coefficient for the metal with the competitive ligand. Much work has been performed to understand $\mathrm{Fe}(\mathrm{III})$ speciation in seawater. For $\mathrm{Fe}(\mathrm{III})$, the $K_{\text {cond } \mathrm{Fe}(\mathrm{III}) \mathrm{L}}$ of a $\mathrm{Fe}-$ natural ligand complex and total natural ligand concentration $\left[C_{\mathrm{L}}\right]$ can be calculated from the intercept and slope of a $\left[\mathrm{Fe}_{\text {labile }}\right] /[\mathrm{FeL}]$ vs. $\left[\mathrm{Fe}_{\text {labile }}\right]$ plot. $\left[\mathrm{Fe}_{\text {labile }}\right]$ is that metal that can bind with the competitive ligand and is obtained from the CSV Fe peak current, $i_{\mathrm{P}}$, and the sensitivity, $S$ (slope of a standard curve in UV seawater); i.e. $\left[\mathrm{Fe}_{\text {labile }}\right]=i_{\mathrm{P}} / S=\left[\mathrm{Fe}^{3+}\right]\left(\alpha_{\mathrm{Fe}^{\prime}}+\alpha_{\mathrm{Fe} 1 \mathrm{~N} 2 \mathrm{~N}}\right)$ and $[\mathrm{FeL}]=C_{\mathrm{Fe}}-$ $\left[\mathrm{Fe}_{\text {labile }}\right]$. The $\alpha_{\mathrm{Fe}^{\prime}}$ is the $\alpha$ coefficient for all inorganic species of $\mathrm{Fe}^{3+}\left(10^{8.4} \text { at } \mathrm{pH}=7 ; 10^{10.0} \text { at } \mathrm{pH}=8\right)^{34}$ and $\alpha_{\mathrm{ML}}$ is the side reaction coefficient for $\mathrm{Fe}(\mathrm{III}) \mathrm{L}$ competitive ligand complexes. For Fe(III) with $1 \mathrm{~N} 2 \mathrm{~N},{ }^{3,12,52}$ the $\alpha_{\mathrm{Fe} 1 \mathrm{~N} 2 \mathrm{~N}}$ is about $10^{13.04}$ at $\mathrm{pH}=7$ and 8 . For salicylaldoxime, ${ }^{6}$ the $\alpha_{\mathrm{FeSal}}$ is about $10^{2}$ at $\mathrm{pH}=8$. The window for determination of $K_{\text {cond } \mathrm{Fe}(\mathrm{III}) \mathrm{L}}$ is smaller that the ASV method (about two log units) but can be varied by changing the ligand concentration. The low $\alpha_{\mathrm{FeSal}}$ for salicylaldoxime indicates that the $K_{\text {cond }} \mathrm{Fe}(\mathrm{III}) \mathrm{L}$ calculated is dependent on the accuracy of $\alpha_{\mathrm{Fe}^{\prime}}$ used. Byrne et al. ${ }^{53}$ have estimated a value of $\alpha_{\mathrm{Fe}^{\prime}}$ of $10^{11.5}$ so $K_{\text {cond } \mathrm{Fe}(\mathrm{III}) \mathrm{L}}$ can vary $1.5 \log$ units based on the $\alpha_{\mathrm{Fe}^{\prime}}$ used.

Fig. 3 shows the $\log K_{\text {cond }}$ Fe(III)L data for several model ligands in UV seawater determined by CSV-CLE titrations with the two competitive ligands ( $1 \mathrm{~N} 2 \mathrm{~N}$ and SAL). In these calculations ${ }^{54}$ an $\alpha_{\mathrm{Fe}^{\prime}}$ of $10^{10.0}$ at $\mathrm{pH}=8$ was used. The data show that the $\log K_{\text {cond Fe(II)L }}$ data are similar-usually within one $\log K$ unit-when using either competitive ligand. The use of $1 \mathrm{~N} 2 \mathrm{~N}$ at $\mathrm{pH}=7$, where the Fe1N2N voltammetric peak is most sensitive, does not compromise the data. The main reason for this is the high $\alpha_{\mathrm{Fe} 1 \mathrm{~N} 2 \mathrm{~N}}$ when compared to the $\alpha_{\mathrm{Fe}^{\prime}}$ of $\mathrm{Fe}$ (III) at these $\mathrm{pH}$ values. The vertical lines in Fig. 3A and 3B show the range of reported $\mathrm{Fe}(\mathrm{III}) \mathrm{L} \log K$ values from the world's oceans. Fig. 3 also shows that the model ligands binding Fe(III) give similar $\log K_{\text {cond } \mathrm{Fe}(\mathrm{III}) \mathrm{L}}$ data regardless of their structure. This will be discussed below. 

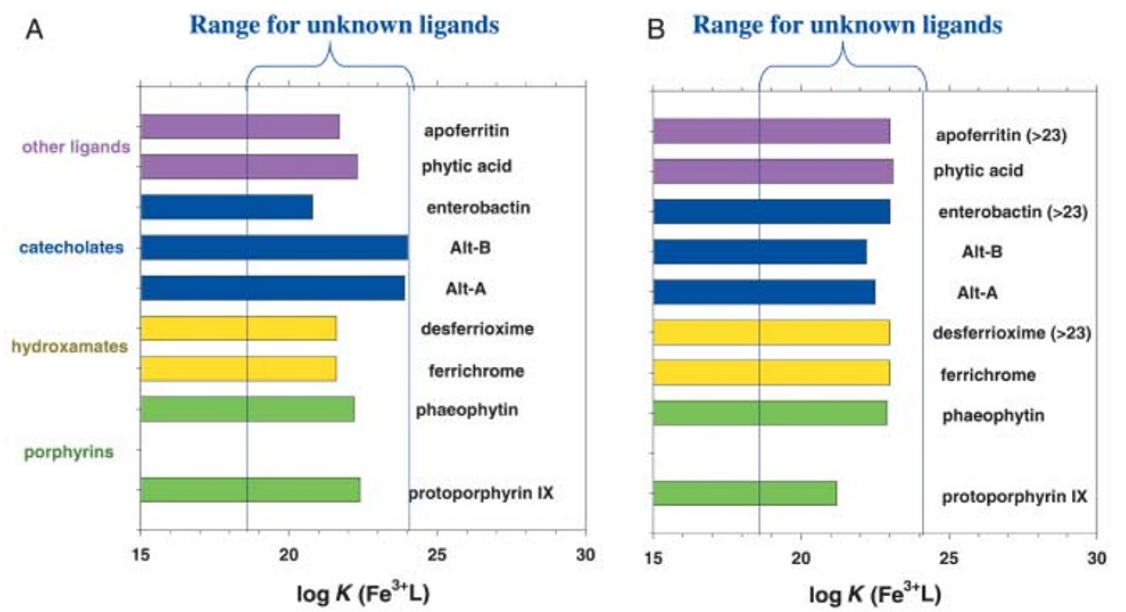

Fig. 3 Data for $\log \mathrm{Fe}_{\text {cond } \mathrm{Fe}(\mathrm{III}) \mathrm{L}}$ complexes (A) CLE-CSV at $\mathrm{pH}=7$ using $1 \mathrm{~N} 2 \mathrm{~N}$ as the competitive ligand and (B) kinetic method at $\mathrm{pH}=8 \mathrm{using}$ $\mathrm{SAL}$ as the competitive ligand.

\section{Kinetic approach}

This approach has been used to assess the rate constants for formation and dissociation of $\mathrm{Fe}(\mathrm{III}) \mathrm{L}$ complexes. The approach is briefly described but is detailed elsewhere. ${ }^{10-12,55}$ Excess $\mathrm{Fe}^{\prime}$ is added to a sample without any competitive ligand so that the excess $\mathrm{Fe}^{\prime}$ can bind to the organic ligand(s) in seawater (eqn. (6)). Aliquots of this solution are measured over time at the $\mathrm{pH}$ of the sample after addition of a competitive ligand to the aliquot. The $k_{\mathrm{f}}$ (rate of formation of $\mathrm{FeL}$ is determined from this experiment) for the excess ligand binding to $\mathrm{Fe}^{\prime}$ is determined by kinetic analysis of the time course.

$$
\mathrm{Fe}^{\prime}+\mathrm{L} \rightarrow \mathrm{FeL}
$$

The $k_{\mathrm{d}}$ and $t_{1 / 2}$ are determined by recovering $\mathrm{Fe}^{\prime}$ in $\mathrm{FeL}$ by adding a competitive ligand such as $1 \mathrm{~N} 2 \mathrm{~N}$ to an equilibrated sample (eqn. (7)). This is monitored over time.

$$
\mathrm{FeL}+3(1 \mathrm{~N} 2 \mathrm{~N}) \rightarrow \mathrm{Fe}(1 \mathrm{~N} 2 \mathrm{~N})_{3}+\mathrm{L}
$$

Eqn. (7) can be broken into two eqn. (8) and (9)

$$
\begin{gathered}
\mathrm{FeL} \rightarrow \mathrm{Fe}^{\prime}+\mathrm{L} \\
\mathrm{Fe}^{\prime}+3(1 \mathrm{~N} 2 \mathrm{~N}) \rightarrow \mathrm{Fe}(1 \mathrm{~N} 2 \mathrm{~N})_{3}
\end{gathered}
$$

The $k_{\mathrm{d}}$ is evaluated using the steady state approximation for $\mathrm{Fe}^{\prime}$ which simplifies the kinetic expression to $\ln [\mathrm{FeL}]=k_{\mathrm{d}} t$. The
$K_{\text {cond } \mathrm{Fe}^{\prime} \mathrm{L}}=k_{\mathrm{f}} / k_{\mathrm{d}}$ and $K_{\text {cond } \mathrm{Fe}(\mathrm{III}) \mathrm{L}}=K_{\text {cond } \mathrm{Fe}^{\prime} \mathrm{L}}\left(\alpha_{\mathrm{Fe}^{\prime}}\right)$ where $\alpha_{\mathrm{Fe}^{\prime}}=10^{10}$. Fig. 4 shows the $\log K_{\text {cond } \mathrm{Fe}(\mathrm{III}) \mathrm{L}}$ data obtained from the kinetic approach at $\mathrm{pH}=8$ and the CSV-CLE approach for model ligands bound to Fe(III) in UV seawater. The agreement is excellent indicating that both methods give comparable results. To date the window for $K_{\text {cond Fe(III)L using }}$ this method is $\log K 18-23$. In addition to the stability constant data, the kinetic data for $\mathrm{Fe}^{\prime} \mathrm{L}$ (Table 1) reflect the fast reaction rates via $k_{\mathrm{f}}$ and slow dissociation rates via $k_{\mathrm{d}}$. The $t_{1 / 2}$ and residence times for $\mathrm{Fe}(\mathrm{III}) \mathrm{L}$ complexes come directly from the $k_{\mathrm{d}}$ data $\left(t_{1 / 2} \times k_{\mathrm{d}}=0.693\right)$ and correlate with other estimates of iron residence times in the ocean. ${ }^{56,57}$

These CSV-CLE and kinetic data as well as solubility data $^{58,59}$ indicate that $\mathrm{Fe}$ (III) is primarily complexed by natural organic compounds in seawater.

\section{Pseudovoltammograms and chelate scales}

Metal reduced to an amalgam; e.g. $\mathrm{ZnL}+2 \mathrm{e}^{-} \rightarrow \mathrm{Zn}(\mathrm{Hg})+$ L. When a metal-ligand complex is reduced to a metal amalgam, the half-wave potential of a metal complex, $E_{1 / 2}$, or the peak potential, $E_{\mathrm{p}}$, can be directly related to the thermodynamic stability constant, $K_{\text {therm }},{ }^{45-48}$ by eqn. (10):

$$
E_{1 / 2}{ }^{\prime}=E_{1 / 2}-\left[2.303 R T \log K_{\text {therm }}\right] / n F
$$

where $E_{1 / 2}$ is the reduction potential of the free metal ion and $n$ is the number of electrons involved in the process and $K_{\text {therm }}=K_{\mathrm{ox}}=[\mathrm{ML}] /\{[\mathrm{M}][\mathrm{L}]\}$ for a $1: 1$ complex (for
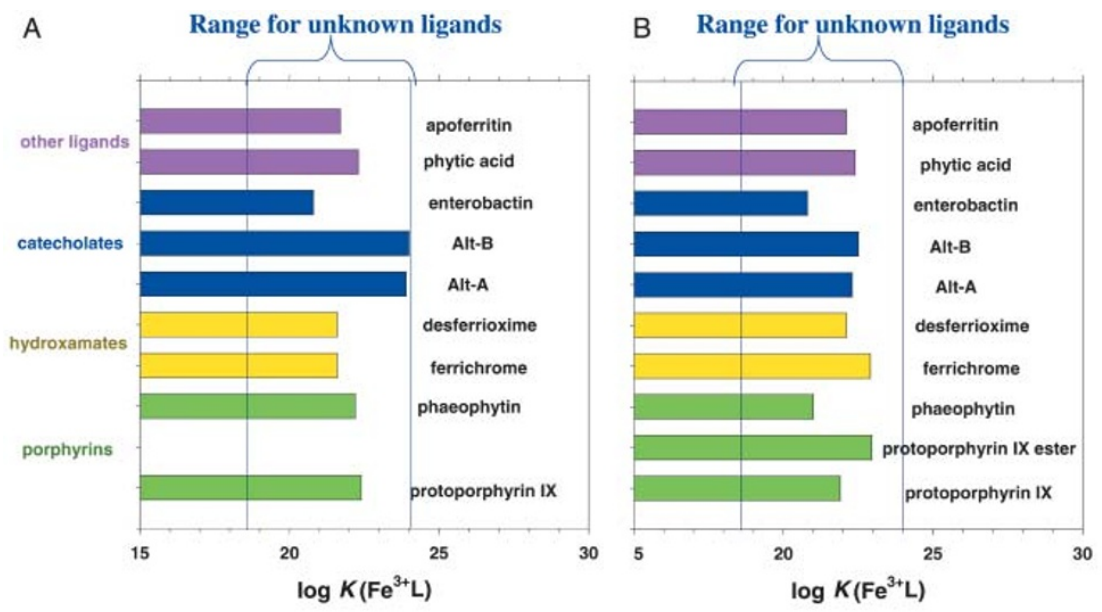

Fig. 4 Data for $\log \mathrm{Fe}_{\text {cond }} \mathrm{Fe}(\mathrm{III}) \mathrm{L}$ complexes (A) CLE-CSV at $\mathrm{pH}=7$ and (B) kinetic method at $\mathrm{pH}=8$ using $1 \mathrm{~N} 2 \mathrm{~N}$ as the competitive ligand. 
Table 1 Comparison of model FeL complex formation and dissociation rate constants, conditional stability constants, and $\mathrm{Fe}^{\prime}$ and $\mathrm{Fe}^{3+}$ residence times in treated with Chelex, photo-irradiated seawater as determined using the kinetic method. Errors represent average mean $\pm s$ (standard deviation) from two separate replicates. ${ }^{1}$ Data taken from ref. 12

\begin{tabular}{|c|c|c|c|c|c|c|c|}
\hline Model ligand & $k_{\mathrm{f}} \times 10^{5} / \mathrm{M}^{-1} \mathrm{~s}^{-1}$ & $k_{\mathrm{d}} \times 10^{-6} / \mathrm{s}^{-1}$ & $\begin{array}{l}\log K_{\mathrm{Fe}^{\prime} \mathrm{L}} \\
\text { kinetic }\end{array}$ & $\begin{array}{l}\log K_{\mathrm{Fe}}{ }^{3+} \mathrm{L} \\
\text { kinetic }\end{array}$ & $\begin{array}{l}\mathrm{Fe}^{\prime} \text { residence } \\
\text { time/yr }\end{array}$ & $\begin{array}{l}\mathrm{Fe}^{3+} \text { residence } \\
\text { time/yr }\end{array}$ & $\log K_{\text {therm }}$ \\
\hline Protoporphyrin $\mathrm{IX}^{a}$ & $6.2 \pm 0.8$ & $0.7 \pm 0.7$ & $11.9 \pm 0.5$ & $21.9 \pm 0.5$ & 0.031 & 645 & - \\
\hline $\begin{array}{l}\text { Protoporphyrin IX } \\
\text { Dimethyl ester }^{a}\end{array}$ & $15.3 \pm 0.2$ & $0.2 \pm 0.9$ & $13.0 \pm 0.2$ & $23.0 \pm 0.2$ & 0.116 & 5866 & - \\
\hline Phaeophytin $^{a}$ & $12.2 \pm 0.1$ & $12.3 \pm 16.8$ & $11.0 \pm 1.2$ & $21.0 \pm 1.2$ & 0.002 & 72 & - \\
\hline Apoferritin $^{b}$ & $0.93 \pm 0.3$ & $0.08 \pm 0.04$ & $12.1 \pm 0.1$ & $22.1 \pm 0.1$ & 0.275 & 820 & - \\
\hline Phytic acid ${ }^{c}$ & $12.8 \pm 0.1$ & $0.51 \pm 0.28$ & $12.4 \pm 0.2$ & $22.4 \pm 0.2$ & 0.043 & 1820 & - \\
\hline Alterobactin $\mathrm{A}^{d}$ & $3.8 \pm 0.8$ & $0.17 \pm 0.04$ & $12.3 \pm 0.4$ & $22.3 \pm 0.4$ & 0.129 & 1620 & $49-53^{18}$ \\
\hline Alterobactin $\mathrm{B}^{e}$ & $8.0 \pm 0.6$ & $0.25 \pm 0.02$ & $12.5 \pm 0.3$ & $22.5 \pm 0.3$ & 0.088 & 2330 & $43.6^{48}$ \\
\hline Enterobactin $^{1 f}$ & 10 & 15.8 & 10.8 & 20.8 & 0.013 & 46.0 & $49.0^{20}$ \\
\hline Ferrichrome $^{g}$ & $4.6 \pm 2.9$ & $0.05 \pm 0.04$ & $12.9 \pm 0.1$ & $22.9 \pm 0.1$ & 0.439 & 6700 & $29.07^{31}$ \\
\hline Desferrioxamine $^{g}$ & $19.6 \pm 10.1$ & $1.5 \pm 1.8$ & $12.1 \pm 0.6$ & $22.1 \pm 0.6$ & 0.015 & 952 & $30.60^{31}$ \\
\hline
\end{tabular}

Fe complexing moieties for the model ligands: ${ }^{a}$ Porphyrin. ${ }^{b}$ Protein. ${ }^{c}$ Phosphate. ${ }^{d} \beta$-Hydroxyaspartate/catecholate. ${ }^{e}$ Bis-catecholate. ${ }^{f}$ Tris-catecholate. ${ }^{g}$ tris-Hydroxamate.

simplicity). $K_{\text {therm }}$ is corrected for ionic strength effects, the side reaction coefficients of the metal and the ligand in the solution of interest and is a $\mathrm{pH}$ independent constant. This particular form of the Lingane equation assumes: (a) no dependence on the reduced metal since it is an amalgam; thus, the complex is destroyed which is a measure of the bond strength and $K_{\text {therm; }}$; (b) $E_{1 / 2}$ ' is independent of ligand concentration, which can be checked by titrating the metal with ligand until no further change in $E_{1 / 2}{ }^{\prime}$ is observed.

At trace concentrations for metal-ligand complexes, pseudopolarograms or pseudovoltammograms are recorded by performing a stripping experiment. Deposition experiments are performed over a range of potentials and the current recorded at each potential. The range of potentials should provide current values where the analyte is and is not electroactive. Plots of $i v s$. deposition potential $\left(E_{\mathrm{dep}}\right)$ give an "s"-shape Nernstian curve from which $E_{1 / 2}$ can be evaluated. For complexes which give a discrete $E_{1 / 2}$ based on the pseudopolarogram, $E_{1 / 2}^{\prime}$ for the complex is directly related to the decomposition of the metal-ligand complex via $K_{\text {therm }}$ (eqn. (11))

$$
E_{1 / 2}^{\prime}=E_{1 / 2}+\left[R T \ln K_{\text {therm }}\right] / n F
$$

where $E_{1 / 2}$ is the potential of the analyte in the absence of complexation by any organic ligand in the matrix of interest. A plot of $E_{1 / 2}^{\prime} v s . \ln K_{\text {therm }}$ for a series of metal-ligand complexes can be constructed from the literature or from experiment to derive information on $K_{\text {therm }}$ from unknown ligands in natural samples.

Fig. 5A shows SWV peaks for 100 micromolar Zn(II) with NTA and Fig. 5B shows a pseudovoltammogram for 10 nanomolar $\mathrm{Zn}$ (II) with NTA. The data are similar for the $\mathrm{Zn}(\mathrm{NTA})_{2}$ complex. Inorganic $\mathrm{Zn}$ (II) varies because of the much higher concentration in Fig. 5A than Fig. 5B. These data show that inorganic ions in seawater do not bind high concentrations of $\mathrm{Zn}$ (II) effectively. Based on these types of data, a chelate scale $\left(E_{1 / 2} v s . \log K_{\text {therm }}\right)$ can be constructed for $\mathrm{Zn}$ with a variety of ligands. Fig. 6 shows a scale for seven known ligands ${ }^{45}$ covering the range of $\log K_{\text {therm }} 4$ to 18 . These data indicate that the window for estimation of $\log K_{\text {therm }}$ data is much larger for the chelate scale approach than the ASV titration approach. The upper limit for $\log K_{\text {therm }}$ for $\mathrm{Zn}$ as well as other metals is controlled by sodium ion reduction which begins near -1.75 .

Fig. 7A and Fig. 7B show pseudovoltammograms obtained from rainwater (September 5, 1992) and seawater (June 26, 1992) from the mouth of Delaware Bay with the Atlantic Ocean. The rainwater sample shows no organic complexation for $\mathrm{Zn}$ (II) whereas the seawater sample shows that there are two moderate-strength $\mathrm{ZnL}$ complexes at $-1.24 \mathrm{~V}\left(\log K_{\text {therm }}=\right.$ $7.77)$ and $-1.40 \mathrm{~V}\left(\log K_{\text {therm }}=11.45\right.$, respectively. A possible
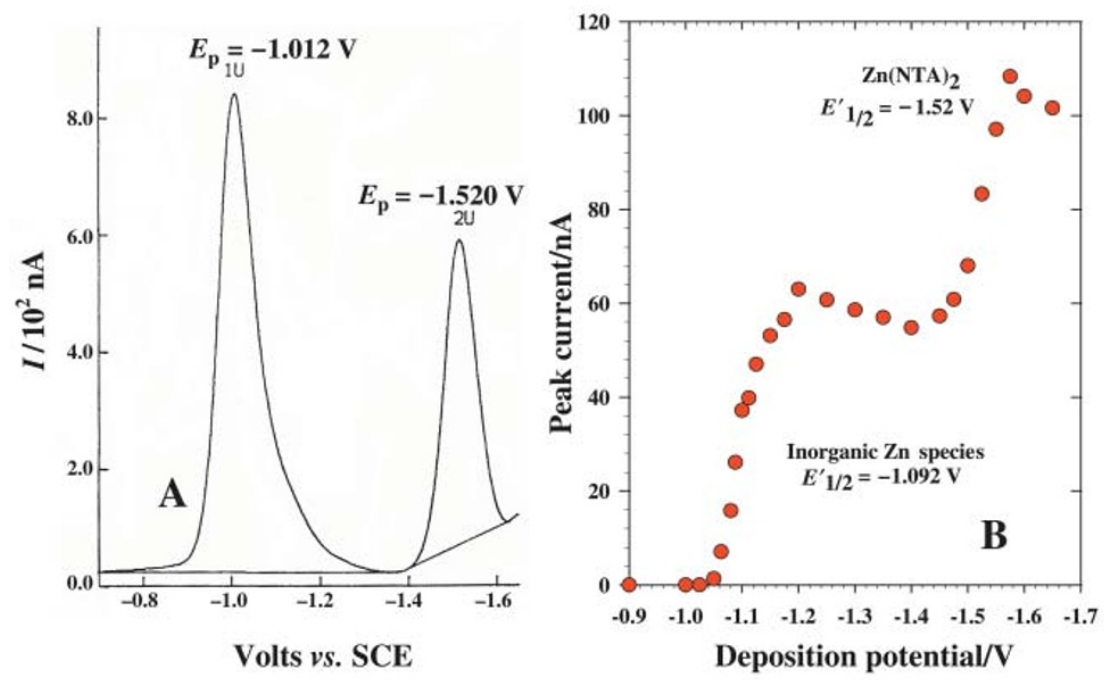

Fig. 5 (A) Square wave voltammogram of $100 \mu \mathrm{M}$ Zn with $50 \mu \mathrm{M}$ NTA and (B) pseudovoltammogram of $10 \mathrm{nM}$ Zn with $500 \mathrm{nM}$ NTA using anodic stripping square wave voltammetry. 


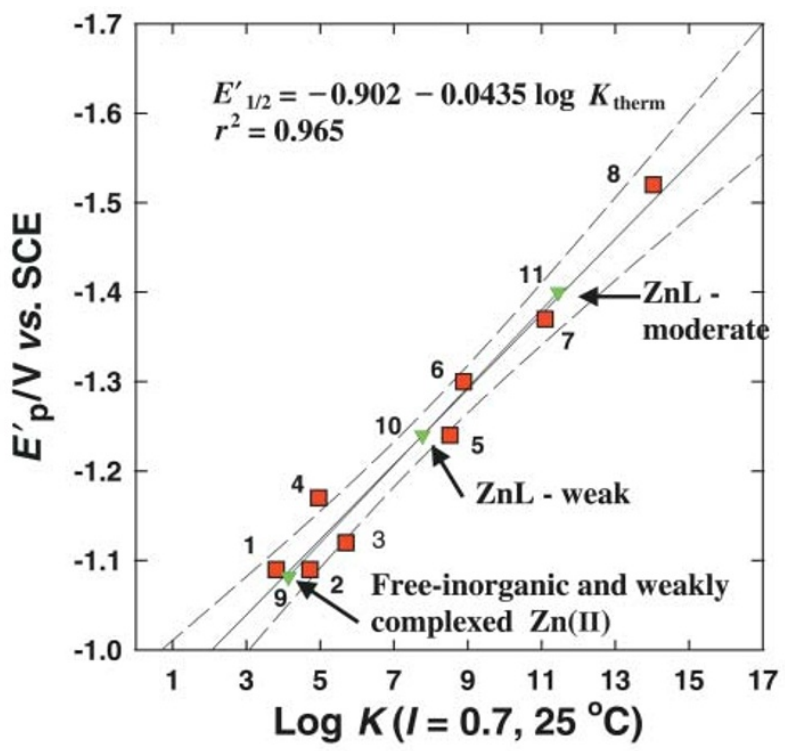

Fig. 6 A plot of $E_{1 / 2}^{\prime}$ from pseudovoltammograms $v s$. $\log K_{\text {therm }}$ for $\mathrm{Zn}$-organic complexes dissolved in seawater. $1=$ oxalic acid; $2=\mathrm{CTP} ; 3=$ ethylenediamine; $4=$ glycine; $5=8$-hydroxyquinoline; $6=$ iminobis(methylenephosphonic acid); $7=$ EDDA; $8=$ NTA as $\mathrm{Zn}(\mathrm{NTA})_{2}$. The numbers 9-11 refer to unknown complexes in Delaware Bay waters (see Fig. 7).

weak third-ligand complex at $-1.082 \mathrm{~V} \quad\left(\log K_{\text {therm }}=\right.$ $\left.4.14 \mathrm{M}^{-} 1\right)$ is due to inorganic ligands and/or weak acids such as oxalate. The $\mathrm{Zn}$ concentration bound to each of these complexes in increasing negative potential is $1.7,0.90$ and $3.5 \mathrm{nM}(5.7 \mathrm{nM}$ combined based on the $\mathrm{Zn}$ peak sensitivity) whereas the total $\mathrm{Zn}$ concentration in the sample is $24.7 \mathrm{nM}$. Thus, $19 \mathrm{nM}$ of complexed $\mathrm{Zn}$ compounds are still unaccounted for. This could be due to strong organic complexes $\left(\log K_{\text {therm }}>18\right)$ or multinuclear sulfide complexes ${ }^{60}$ which have been found in natural waters that have $\log K_{\text {therm }}$ $>40$. These $\mathrm{Zn}$-ligand complexes cannot be determined by the pseudovoltammetry approach because of sodium ion reduction, which permits an upper limit of $\log K_{\text {therm }}=18$ for $\mathrm{Zn}$.

These data are now compared with the ASV titration approach shown in Fig. 2. The latter method indicates that one complex (perhaps a second) with ligand in excess to the metal is present with a value for the conditional $\log K_{\text {cond }} \mathrm{ML}=9.03$.
The conditional $K_{\text {cond }} \mathrm{ML}$ and $K_{\text {therm }}$ data are not readily comparable for $\mathrm{Zn}$ (II) because $K_{\text {therm }}$ data are due to the actual ligand complexes in the sample and $K_{\text {cond }} \mathrm{ML}_{\text {data }}$ are for the ligands in excess to the metal in seawater. The actual ligands binding $\mathrm{Zn}$ may or may not be the same as the excess ligands to total $\mathrm{Zn}$ in the sample. The $\log K_{\text {therm }}$ data that are less than 9.03 are weak complexes that are not detected by both Langmuir and Scatchard linear transformations. The complex with $\log K_{\text {therm }}=11.45$ (close to the ZnEDDA complex) ${ }^{45}$ may not be related to the $\log K_{\text {cond ML }}$ data of 9.03 either because the actual ligand concentration binding $\mathrm{Zn}$ in this case via the pseudovoltammograms is smaller than the ASV titration calculation of $36.1 \mathrm{nM}$. Thus, the two methods appear to be giving information on different $\mathrm{Zn}$ complexes.

A similar approach has been used for $\mathrm{Cu}(\mathrm{II})^{46}$ as shown in Fig. 8. In that study, 17 known organic ligands were used to develop a chelate scale with a $\log K_{\text {therm }}$ range of $12-26.5$. The upper limit for this scale based on the sodium reduction wave is $\log K_{\text {therm }} \sim 49$. Interestingly, the largest $\log K_{\text {therm }}$ value for a $\mathrm{CuL}$ ligand is smaller than the estimated $\mathrm{CuL}$ data from field and culture samples ( $E_{1 / 2}^{\prime}$ is more negative for the field samples) demonstrating that very strong $\mathrm{CuL}$ complexes can be formed. The strong CuL complex found in Martha's Vineyard waters was matched by a ligand produced by a strain of Synechoccous. The moderately strong CuL complex in Eel's Pond and in Martha's Vineyard waters did not match the ligands from other cultures. The three cultures tested showed a great variability of ligands that can be produced by different organisms. The log $K_{\text {cond Cu(II)L }}$ for these complexes as determined by ASV titration ranged from 10.8 to 14.3 . These conditional constants indicate that the side reaction coefficients for the ligand(s) are high and similar to what has been observed for ligands that form Fe(III) complexes, which are discussed below.

Reduction of a metal complex to a lower valency (no amalgam formation) $\mathbf{F e}^{3+} \mathbf{L}+\mathbf{e}^{-} \leftrightarrow \mathbf{F e}^{2+} \mathbf{L}$. Similar chelate scale data can be obtained for metal complexes which do not decompose at the electrode to form metal amalgams. ${ }^{47,48}$ In this case, $E_{1 / 2}$ is proportional to the ratio of the thermodynamic stability constants of the reduced and oxidized complexes according to eqn. (12):

$$
E_{1 / 2}^{\prime}=E_{1 / 2}-[2.303 R T / n F] \log K_{\mathrm{ox}} / K_{\text {red }}
$$

where $K_{\text {ox }}$ and $K_{\text {red }}$ are the stability constants of $\mathrm{Fe}^{3+} \mathrm{L}$ and

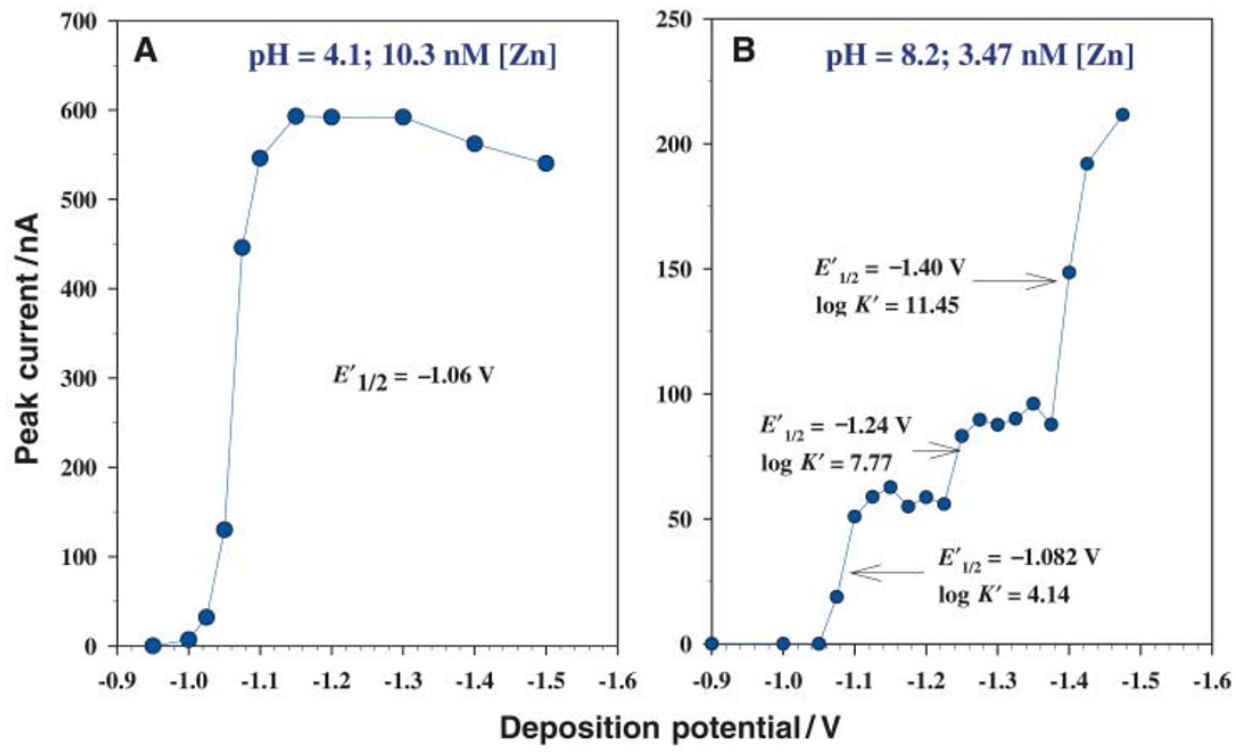

Fig. 7 (A) Pseudovoltammogram of a rainwater sample from Lewes, Delaware on 5 September 1992; (B) pseudovoltammogram of Delaware Bay water on 26 June 1992. 


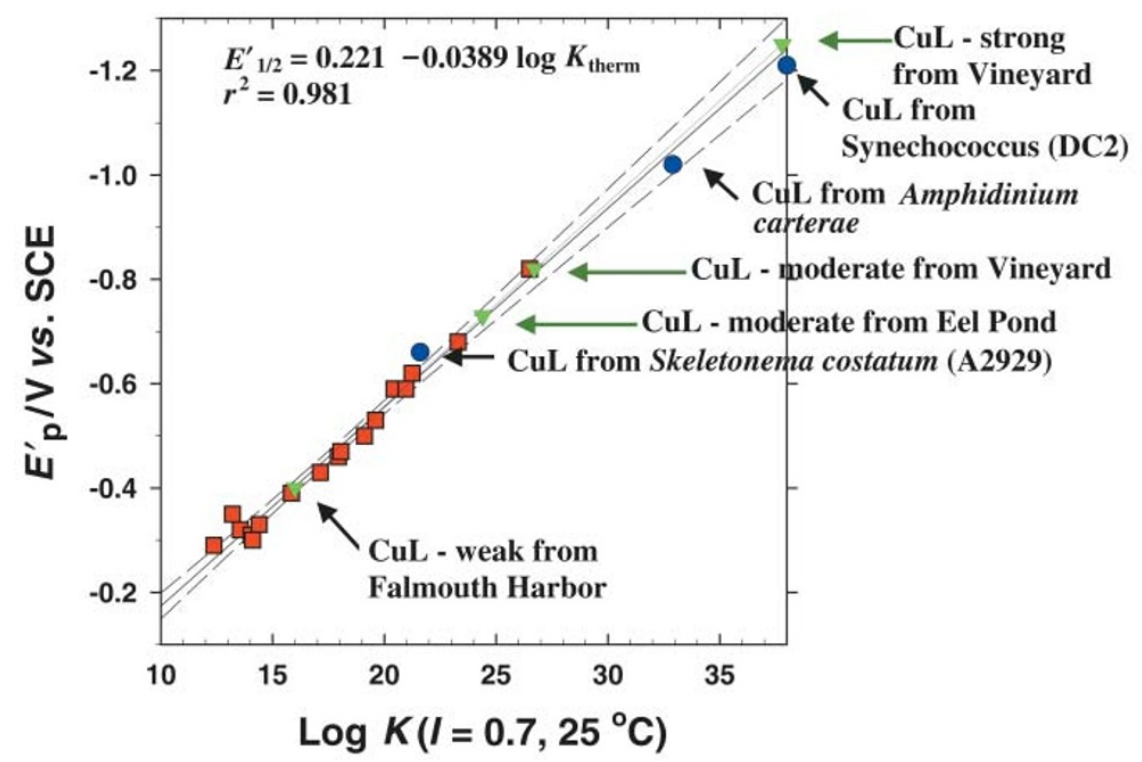

Fig. 8 A plot of $E_{1 / 2}^{\prime}$ from pseudovoltammograms $v s . \log K_{\text {therm }}$ for Cu(II)-organic complexes dissolved in seawater. Blue symbols are from cultures and green symbols are from natural waters as indicated.

$\mathrm{Fe}^{2+} \mathrm{L}$, respectively. If the $K_{\text {red }}$ values for all complexes are similar as shown for $\mathrm{Fe}(\mathrm{III})$ then the $K_{\text {red }}$ term can be incorporated into the intercept and the equation simplifies to eqn. (13):

$$
\begin{aligned}
E^{\prime}{ }_{1 / 2}= & {\left[E_{1 / 2}+(2.303 R T / n F) \log K_{\mathrm{red}}\right] } \\
& -2.303 R T / n F \log K_{\mathrm{ox}}
\end{aligned}
$$

For this case the electrode processes are reversible (checked by CV or SWV) because the complex does not dissociate or become destroyed, and $E_{1 / 2}^{\prime}$ is independent of the ligand concentration (check by titrating the metal with ligand until no further change in $E_{1 / 2}^{\prime}$ is observed).

A chelate scale for $\mathrm{Fe}(\mathrm{III})^{47}$ has been developed using seven natural ligands (Table 2 and Fig. 9) which react with Fe(III) to form complexes spanning $20 \log K_{\text {therm }}$ units. For this example we discuss the binding properties with regard to eqn. (2). The

Table 2 Electrochemical and stability constant data for $\mathrm{Fe}(\mathrm{III})$ complexes with selected "model" ligands ${ }^{47}$ and natural siderophores. ${ }^{48}$ Measurements were made in $5 \mathrm{mM}$ Bistris buffer adjusted to $0.1 \mathrm{M}$ ionic strength with $\mathrm{NaCl}$

\begin{tabular}{llll}
\hline Complex $^{a}$ & $\mathrm{pH}$ & $E_{\mathrm{p}}^{\prime}{ }^{b} / \mathrm{V} v$ s. SCE & $\begin{array}{l}\log K_{\mathrm{i}}^{c} \\
\left(I=0.1,25^{\circ} \mathrm{C}\right)\end{array}$ \\
\hline
\end{tabular}

Model ligands

2. [FeNTAtiron]

3. $[\text { FeNTAcat }]^{2-}$

4. $\left[\mathrm{Fe}(\mathrm{cat})_{2}\right]^{-}$

5. $\left[\mathrm{Fe}(4 \mathrm{Ncat})_{3}\right]^{3-}$

6. $\left[\mathrm{Fe}(\mathrm{cat})_{3}\right]^{3-}$

7. $[\text { Feent }]^{3-}$

$7 \quad-0.145$

30.0

$-0.182$

31.7

$7-0.21$

32.9

$-0.354$

34.7

$\begin{array}{rrr}7 & -0.440 & 40.0 \\ 10 & -0.680 & 43.7\end{array}$

Siderophores

8. $\left[\mathrm{Fe}(\text { Alt-B })_{2}\right]$

9. $\left[\mathrm{Fe}(\mathrm{Alt}-\mathrm{B})_{2}\right]$

$-0.924$

49.0

10. Fe-PCC7002 No. 1

11. Fe-PCC7002 No. 3

12. Decapeptides mefp1

13. mefp1

6

${ }^{a}$ CDTA $=$ cis-1,2-cyclohexylenedinitrilotetraacetate, NTA $=$ nitrilotriacetate, tiron $=4,5$-dihydoxy-1,3-benzene disulfonic acid, cat $=$ catechol, $4 \mathrm{Ncat}=4$-nitrocatechol, ent $=$ enterobactin, Alt-B $=$ alterobactin B, PCC7002 = Synechococcus sp. PCC7002 isolates (complex stoichiometry is not known for eqn.(10) and (11)). ${ }^{b} \pm 10 \mathrm{mV}$. ${ }^{c}$ See Table 1 of ref. 47 for references. first 3 complexes contain CDTA or NTA with or without a catechol. The low $E_{\mathrm{p}}$ and $\log K$ reflect that carboxylic acids do not bind (lower $\Delta H$ ) with $\mathrm{Fe}$ (III) like the other complexes which contain only catechol functional groups. $\mathrm{Fe}(\mathrm{cat})_{2}{ }^{-}$is stronger than these but weaker that the tris-catechol complexes. The nitro-catechol binds more weakly in the tris complex to Fe(III) than catechol because the nitro group is an electron withdrawing group. The enterobactin complex with Fe(III) shows the stronger binding effect of one molecule with three catechol groups than three separate catechol ligands. This is related to entropic effects via the "chelate" effect. ${ }^{49}$ For example, $\mathrm{Fe}(\mathrm{cat})_{3}{ }^{3-}$ and $\mathrm{Fe}(\mathrm{ent})^{3-}$ have the following reactivity [eqn. (14a) and (14b)] based on Fe(III).

$$
\begin{gathered}
\mathrm{Fe}\left(\mathrm{H}_{2} \mathrm{O}\right)_{6}^{3+}+3 \mathrm{cat}^{2-} \rightarrow \mathrm{Fe}(\mathrm{cat})_{3}^{3-}+6 \mathrm{H}_{2} \mathrm{O} \\
\mathrm{Fe}\left(\mathrm{H}_{2} \mathrm{O}\right)_{6}^{3+}+\mathrm{ent}^{6-} \rightarrow \mathrm{Fe}(\mathrm{ent})^{3-}+6 \mathrm{H}_{2} \mathrm{O}
\end{gathered}
$$

The larger $\log K_{\text {therm }}$ reflects that $\Delta G$ is controlled by $\Delta S$ in

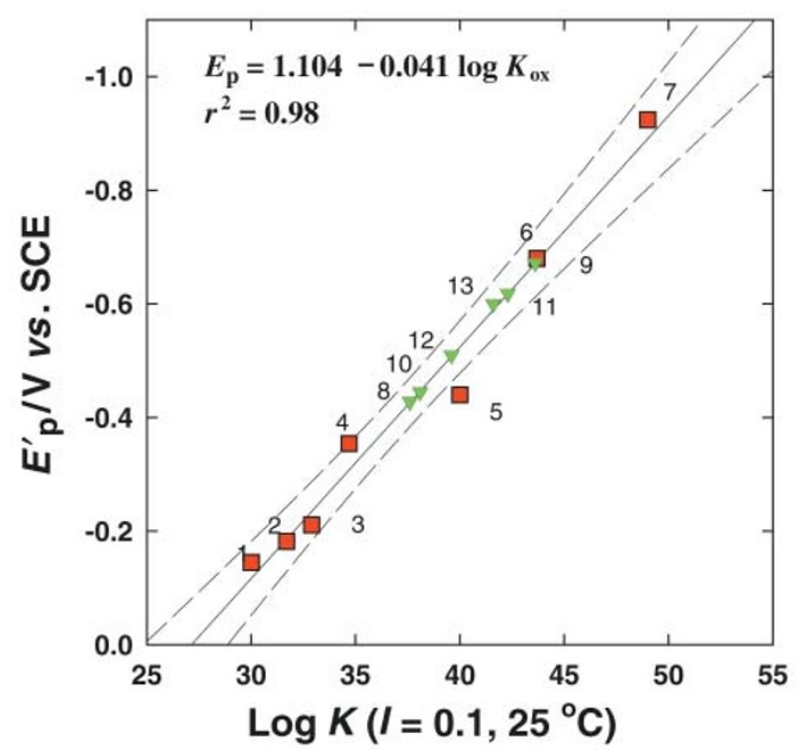

Fig. 9 A plot of $E_{\mathrm{p}}^{\prime}$ from square wave voltammograms vs. $\log K_{\text {therm }}$ for $\mathrm{Fe}(\mathrm{III})$-organic complexes dissolved in $0.1 \mathrm{M} \mathrm{KCl}$. Numbers refer to compounds in Table 2. 
eqn.(14b) because the $\Delta H$ term for catechol functional groups is similar for eqn.(14a) and (14b). These data suggest that $k_{\mathrm{d}}$ for the $\mathrm{Fe}(\mathrm{ent})^{3-}$ containing a tris-catechol structure is smaller than for three separate catechol groups in $\mathrm{Fe}(\mathrm{cat})_{3}{ }^{3-}$. Because $K=k_{\mathrm{f}} / k_{\mathrm{d}}, K$ and $\Delta G$ increase with smaller $k_{\mathrm{d}} \cdot{ }^{49}$

Fig. 9 also shows data for catechol ligands produced by different organisms. ${ }^{47,48}$ Mytilus edulis produces a $100 \mathrm{kDa}$ foot protein (mefp1) which contains several catechol groups. It is not known how many catechol groups bind to $\mathrm{Fe}$ (III) in the protein but $E_{\mathrm{p}}$ and $\log K_{\text {therm }}$ are larger than the bis-catechol $\mathrm{Fe}(\mathrm{III})$ complexes. Tryptic digests of the foot protein produce decapeptides that react to form $\mathrm{FeL}_{2}$, bis-catechol complexes, as in Fig. 10. These bind more strongly with Fe(III) than two catechols in $\mathrm{Fe}(\mathrm{cat})_{2}{ }^{-}$and this stronger binding appears related to interaction of the peptide chains with each other which helps to lower $k_{\mathrm{d}}$. Similar results ${ }^{47}$ have been noted for the bis(catechol) complex of alterobactin-B from Alteromonas luteoviolacea.

These data show that the known ligands have a significant difference in $\log K_{\text {therm. }}$. However, these ligands and other known $\mathrm{Fe}(\mathrm{III})$ binding ligands have remarkably similar $\log K_{\text {cond } \mathrm{Fe}(\mathrm{III}) \mathrm{L}}$ values (Fig. 3 and 4) despite having different structures. This suggests that proton loss from the ligand and not $\mathrm{Mg}, \mathrm{Ca}$ binding are important for the binding of $\mathrm{Fe}$ by the ligand. The side reaction coefficients for these ligands differ in such a way that when correcting for proton effects, the $K_{\text {therm }}$ data is different. The model ligands range from catecholate groups, which have 2 protons per functional group ( 6 total for enterobactin), to one proton per functional group for hydroxamates ( 3 total for desferrioxamine because there is no proton attached to the $\mathrm{C}=\mathrm{O}$ group). The three proton difference for enterobactin (also alterobactin-A) vs. that for desferrioxamine leads to a different $K_{\text {therm }}$. In addition, porphyrins have 2 protons per functional group and all four $\mathrm{N}$ atoms can bind $\mathrm{Fe}$. The effect of losing 6 protons from Alterobactin-A, 3 protons from desferrioxamine and 2 protons from a porphyrin lead to similar $\log K_{\text {cond }} \mathrm{Fe}(\mathrm{III}) \mathrm{L}$.

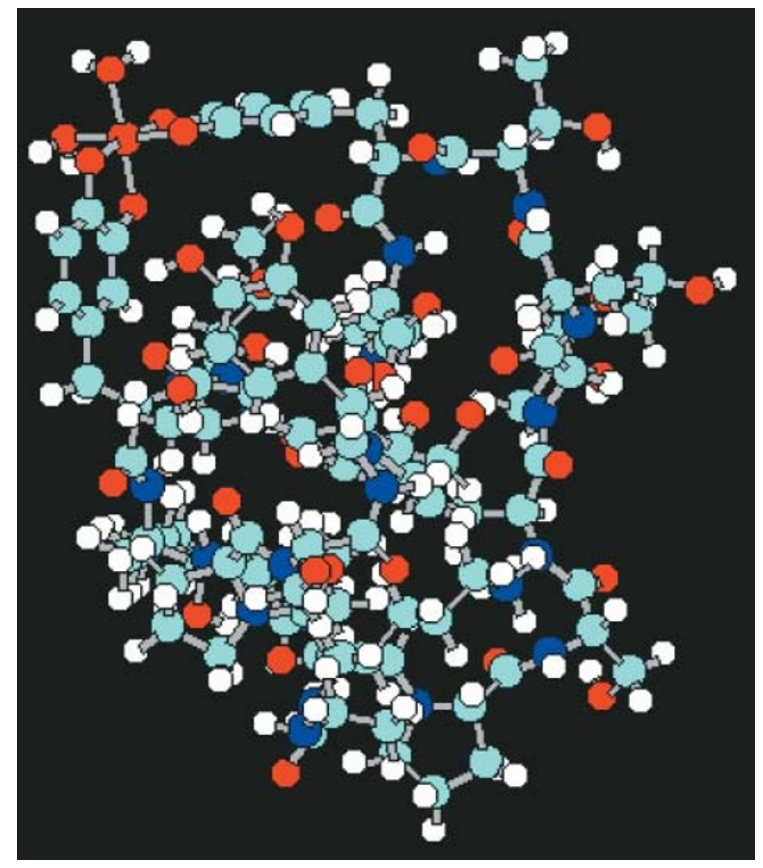

Fig. 10 Hyperchem $\mathrm{MM}+2$ calculation for the $\mathrm{FeL}_{2}$ complex from a decapeptide prepared from Mytilus edulis foot protein 1. The two decapeptide ligands appear to interact to stabilize the complex and prevent dissociation. The $\log K_{\text {therm }}$ estimated is $40.2 v s .34 .7$ for the bis(catechol) complex. The $\mathrm{Fe}$ atom bound to six oxygen atoms is in the upper left part of the figure.

\section{Conclusions}

The ASV and CSV-CLE methods for the determination of organic-metal complexation give similar results for $K_{\text {cond }} \mathrm{ML}$ and ligand concentration. These data relate to the ligand in excess to the metal in solution. ASV titrations have a larger $K_{\text {cond }}$ ML window than CSV-CLE, which can be varied by changing the competing ligand concentration. The excess ligand may or may not be the same as the actual ligand in the metal-ligand complex in the sample. The pseudovoltammogram method gives $K_{\text {therm }}$ and ligand concentration data on the actual complex(es) in solution within the window limited by the reduction of sodium ion. The data from the titration methods and the pseudovoltammogram data are not necessarily similar as shown for $\mathrm{Zn}$. For Fe(III), the choice of competitive ligand for the CSV-CLE methods does not appear to affect the $\log K_{\text {cond }} \mathrm{Fe}(\mathrm{III}) \mathrm{L}$ data. The kinetic approach also agrees with the CSV-CLE methods. These similarities are due to measuring the same ligand types; i.e. excess ligand to the metal in the sample.

\section{Acknowledgements}

This work was supported by two grants from the National Science Foundation (OCE-9730334 and OCE-9714302). We wish to congratulate Frank Millero on receiving the first ACS Division of Geochemistry award and for his encouragement over the years.

\section{Appendix}

\section{Appendix 1}<smiles>O=C([O-])C(=O)O</smiles>

Oxalate<smiles>NCCN</smiles>

EN

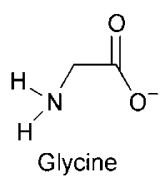

Glycine<smiles>Nc1ccc(C2OC(COP(=O)(O)OP(=O)(O)OP(=O)(O)O)C(O)C2O)c(=O)[nH]1</smiles><smiles>[O-]c1cccc2cccnc12</smiles>

8-Hydroxyquinoline<smiles>[O-][P+]1=[O+][P-]([O-])CNC1</smiles>

Iminobis(methylenephosphonic acid)<smiles>O=C([O-])CNCCNCC(=O)O</smiles>

EDDA<smiles>O=C([O-])CN(CC(=O)[O-])CC(=O)[O-]</smiles>

NTA
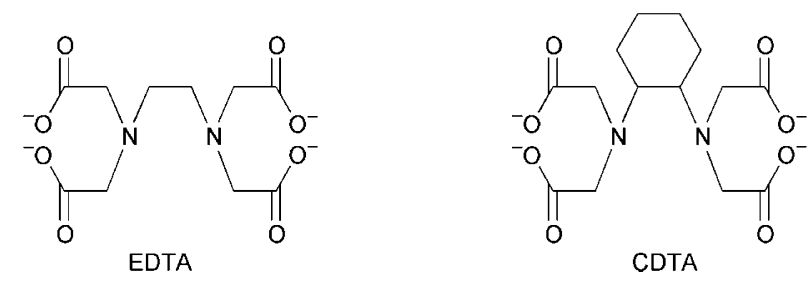


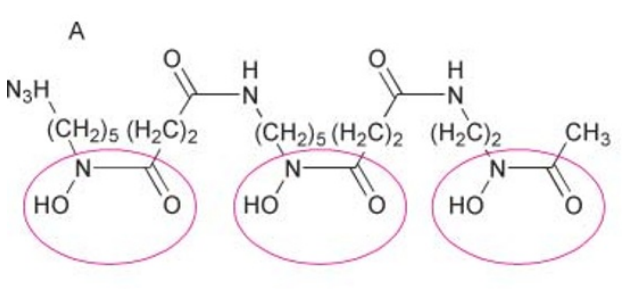

Desferrioxamine B

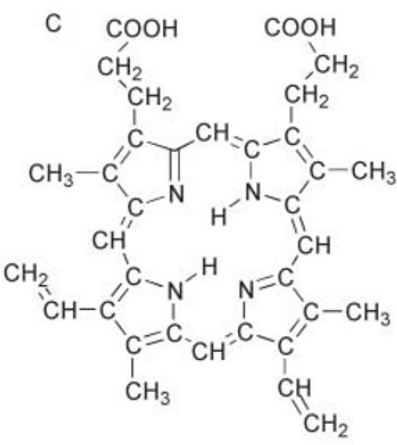

Protoporphyrin

\section{References}

1 K. W. Bruland, R. P. Franks, G. A. Knauer and J. H. Martin, Anal. Chim. Acta, 1979, 105, 233.

2 K. W. Bruland, Limnol. Oceanogr., 1989, 34, 176.

3 M. Gledhill and C. M. G. van den Berg, Mar. Chem., 1994, 47, 41

4 C. M. G. Van den Berg, M. Nimmo, O. Abollino and E. Mentasti, Electroanalysis, 1991, 3, 477.

5 P. B. Kozelka and K. W. Bruland, Mar. Chem., 1998, 60, 267.

6 E. L. Rue and K. W. Bruland, Mar. Chem., 1995, 50, 117.

7 E. L. Rue and K. W. Bruland, Limnol. Oceanogr., 1997, 42, 901.

8 M. A. Saito and J. W. Moffett, Mar. Chem., 2001, 75, 49.

9 M. J. Ellwood and C. M.G. van den Berg, Mar. Chem., 2001, 75, 33

10 A. E. Witter and G. W. Luther III, Mar. Chem., 1998, 62, 241.

11 A. E. Witter, B. L. Lewis and G. W. Luther III, Deep Sea Res., 2000, 47, 1517.

12 J. Wu and G. W. Luther III, Mar. Chem., 1995, 50, 159.

13 M. G. Haygood, P. D. Holt and A. Butler, Limnol. Oceanogr., 1993, 38, 1091.

14 J. S. Martinez, G. P. Zhang, P. D. Holt, H.-T. Jung, C. J. Carrano, M. G. Haygood and A. Butler, Science, , 287, 1245.

15 S. W. Wilhelm, D. P. Maxwell and C. G. Trick, Limnol. Oceanogr., 1996, 41, 89.

16 S. W. Wilhelm, K. MacAuley and C. G. Trick, Limnol. Oceanogr., 1997, 43, 992.

17 R. T. Reid and A. Butler, Limnol. Oceanogr., 1991, 36, 1783.

18 R. T. Reid, D. H. Live, D. J. Faulkner and A. Butler, Nature, 1993 , 366, 455.

19 M. Hofte, Classes of microbial siderophores, in Iron chelation in plants and soil microorganisms, ed. L. L. Barton and B. C. Hemming, Academic Press, Inc., San Diego, CA, 1993, p. 4.

20 L. D. Loomis and K. N. Raymond, Inorg. Chem., 1991, 30, 906.

21 G. B. Wong, M. J. Kappel, K. N. Raymond, B. Matzanke and G. J. Winkelmann, J. Am. Chem. Soc., 1983, 105, 810.

22 D. A. Hutchins, W. X. Wang and N. S. Fisher, Limnol. Oceanogr., 1995, 40, 989

23 D. A. Hutchins, Prog. Physiol. Res., 1995, 11, 1.

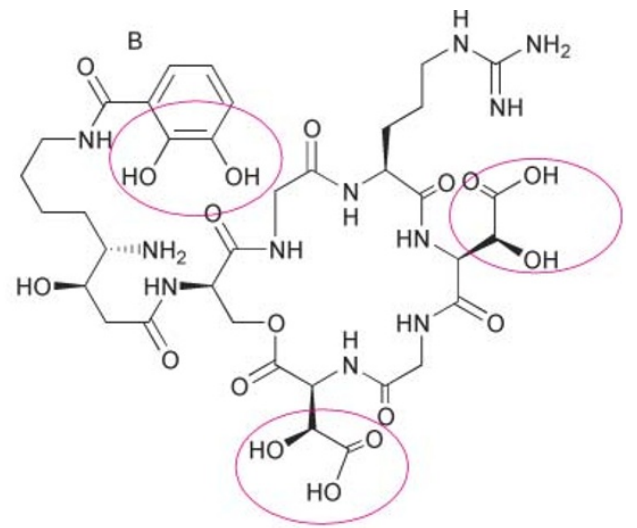

Alterobactin A

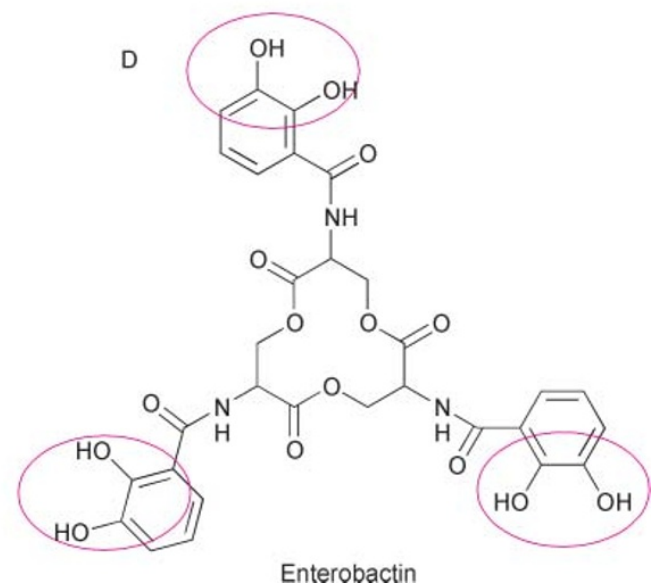

24 D. A. Hutchins, A. E. Witter, A. Butler and G. W. Luther III, Nature, 1999, 400, 858.

25 D. A. Hutchins and K. W. Bruland, Mar. Ecol. Prog. Ser., 1994, 110, 259.

26 C. J. Gobler, D. A. Hutchins, N. S. Fisher, E. M. Cosper and S. A. Sanudo-Wilhelmy, Limnol. Oceanogr., 1997, 42, 1492.

27 S. E. Palmer and E. W. Baker, Science, 1978, 201, 49.

28 M. Suzumura and A. Kamatani, Geochim. Cosmochim. Acta, 1995, 59, 1021.

29 M. Suzumura and A. Kamatani, Limnol. Oceanogr., 1995, 40, 1254

30 E. C. Theil, Ann. Rev. Biochem., 1987, 56, 289.

31 A. L. Crumbliss, Aqueous solution equilibrium and kinetic studies of iron siderophore and model siderophore complexes, in $C R C$ Handbook of Microbial Iron Chelates, ed. G. Winkelmann, CRC Press, Boca Raton, FL, 1991, pp. 177-232.

32 J. Hering and F. M. M. Morel, Geochim. Cosmochim. Acta, 1989, 45, 855 .

33 R. J. M. Hudson and F. M. M. Morel, Deep-Sea Res., 1993, 40, 129.

34 R. J. M. Hudson, D. T. Covault and F. M. M. Morel, Mar. Chem., 1992, 38, 209.

35 W. G. Sunda and P. A. Gillespie, J. Mar. Res., 1979, 37, 761.

36 A. Butler, Science, 1998, 281, 207.

37 K. W. Bruland, J. R. Donat and D. A. Hutchins, Limnol. Oceanogr., 1991, 36, 1555.

38 I. Ruzic, Anal. Chim. Acta, 1982, 140, 99.

39 I. Ruzic, Kinetics of complexation and determination of complexation parameters in natural waters, in Complexation of trace metals in natural waters, ed. C. J. M. Kramer and J. C. Duinker, Dr W Junk Publishers, The Hague, 1983, pp. 131-147.

40 C. M. G. Van den Berg, Mar. Chem., 1984, 15, 1.

41 C. M. G. Van den Berg and J. R. Donat, Anal. Chim. Acta., 1992, 257, 281.

42 L. J. A. Gerringa, P. M. J. Herman and T. C. W. Poortvliet, Mar. Chem., 1995, 48, 131.

43 L. A. Miller and K. W. Bruland, Anal Chim Acta, 1997, 343, 161. 
44 J. R. Donat and K. W. Bruland, Mar. Chem., 1990, 28, 301.

45 B. L. Lewis, G. W. Luther III, H. Lane and T. M. Church, Electroanalysis, 1995, 7, 166.

46 P. L. Croot, J. W. Moffett and G. W. Luther III, Mar. Chem., 1999, 67, 219.

47 S. W. Taylor, G. W. Luther III and J. H. Waite, Inorg. Chem., 1994, 33, 5819.

48 B. L. Lewis, P. D. Holt, S. W. Taylor, S. W. Wilhelm, C. G. Trick, A. Butler and G. W. Luther III, Mar. Chem., 1995, 50, 179.

49 D. F. Shriver, P. Atkins and C. H. Langford, Inorganic Chemistry, W. H. Freeman and Co., NY, 2nd edn., 1994, p. 819.

50 C. F. J. Baes and R. E. Messmer, The hydrolysis of cations. A critical review of hydrolytic species and their stability constants in aqueous solution, Wiley, New York, 1976, pp. 229-237.

51 D. R. Turner, M. Whitfield and A. G. Dickson, Geochim. Cosmochim. Acta, 1981, 45, 855.
52 C. M. G. Van den Berg, Mar. Chem., 1995, 50, 139.

53 R. H. Byrne, L. R. Kump and K. J. Cantrell, Mar. Chem., 1988, 25, 163.

54 A. E. Witter, D. A. Hutchins, A. Butler and G. W. Luther III, Mar. Chem., 2000, 69, 1.

55 G. W. Luther III and J. Wu, Mar. Chem., 1997, 57, 173.

56 K. S. Johnson, R. M. Gordon and K. H. Coale, Mar. Chem., 1997, 57, 137.

57 K. S. Johnson, R. M. Gordon and K. H. Coale, Mar. Chem., 1997, 57, 181.

58 F. J. Millero, Earth Planet. Sci. Lett., 1998, 154, 323.

59 K. Kuma, J. Nishioka and K. Matsunaga, Limnol. Oceanogr., 1996, 41, 396.

60 T. F. Rozan, M. E. Lassman, D. P. Ridge and G. W. Luther III, Nature, 2000, 406, 879. 